\title{
Questioning Curriculum Theory in Teacher Education: Nourishing and Invisibly Repairing the Minds of Researchers and Teachers
}

\author{
Peter P. Grimmett \\ Department of Curriculum and Pedagogy, University of British Columbia, Vancouver, Canada \\ Email: peter.grimmett@ubc.ca
}

How to cite this paper: Grimmett, P. P. (2017). Questioning Curriculum Theory in Teacher Education: Nourishing and Invisibly Repairing the Minds of Researchers and Teachers. Creative Education, 8, 1124-1134. https://doi.org/10.4236/ce.2017.87081

Received: June 7, 2017

Accepted: June 19, 2017

Published: June 22, 2017

Copyright $\odot 2017$ by author and Scientific Research Publishing Inc. This work is licensed under the Creative Commons Attribution International License (CC BY 4.0).

http://creativecommons.org/licenses/by/4.0/

\begin{abstract}
I begin by posing the following question: Whatever happened to curriculum theory in teacher education? My answer is short-it is missing in action, both in the action of research and practice! To address the consequences of this for teacher education research and practice, I use a Wordsworth poem "Spots of Time" to illustrate my premise that we need curriculum theory in teacher education to nourish and invisibly repair both our researching and pedagogical minds. Curriculum theory informs, evokes, provokes, and disrupts our mental frames about teaching. Hence, theoretically informed conceptualizations can enable teacher educators to revisit their practice in a manner that escapes dour and lifeless pedagogy. Such an approach arises when we focus too directly on learning and its measurement to the neglect of understanding how study is the central site of education. This misplaced emphasis leads us into intellectual traps around teaching that educators need to divest themselves in curriculum if we are to become creative and engage students in assiduous study. My argument is that, without this turn, teacher education will remain moribund; and, if teacher education as a viable practice dies, then so too will Faculties of Education. We need curriculum theory to find spots in time whence our minds as teacher education researchers and pedagogues are nourished and invisibly repaired.
\end{abstract}

\section{Keywords}

Curriculum Theory, Teacher Education: Study, Pedagogy, Poetry

\section{Introduction}

In questioning curriculum theory, I pose the following inquiry: Whatever happened to curriculum theory in teacher education? My answer is short-it went 
missing in action, both the action of research and practice! Rather than spend the brief time I have time on musing about why this has happened. I intend to address the consequences of this for teacher education research and practice. In doing so, I shall illustrate my premise that we need curriculum theory in teacher education to nourish and invisibly repair our researching and pedagogical minds. With Bolton (2010), I believe Wordsworth was onto something when he wrote about "Spots of Time" in the $12^{\text {th }}$ book of his poem The Prelude:

\section{Spots of Time}

There are in our existence spots of time,

That with distinct pre-eminence retain

A renovating virtue, whence, depressed

By false opinion and contentious thought,

Or aught of heavier or more deadly weight,

In trivial occupations, and the round

Of ordinary intercourse, our minds

Are nourished and invisibly repaired;

A virtue, by which pleasure is enhanced,

That penetrates, enables us to mount,

When high, more high, and lifts us up when fallen.

This efficacious spirit chiefly lurks

Among those passages of life that give

Profoundest knowledge to what point, and how,

The mind is lord and master-outward sense

The obedient servant of her will. Such moments

\section{Are scattered everywhere.}

(William Wordsworth, 1850, The Prelude, Book XII)

Thesis: Central to a Faculty of Education is teacher education. Take away teacher education and you have precipitated the demise of the Faculty. Central to teacher education is curriculum theory. Take away curriculum theory, and you have precipitated the dissolution of teacher education. Hence, if we value Faculties of Education for the leading and cutting edge research they do, then we need to value both curriculum theory and teacher education enough to create in and through them compelling forms of inquiry and enabling forms of praxis. And in nurturing inquiry and praxis, we find that curriculum theory evokes spots in time whence our minds are nourished and invisibly repaired.

Let me begin to illustrate this thesis with a personal story.

\section{A Choral Experience}

I was the only Bass singer who showed up for choir practice that fated Thursday evening. I always hate being solo because I feel so exposed. For a start, in long phrases, there is no possibility to stagger my breathing, so I end up staggering to the end of a line out of breath! But, more importantly, I have no one to follow. The secret to my success (some would call it coping) has always been to tap into 
my innate musicality, follow on a split second after the Bass section leader (whom I always stand next to) and, upon finding the note and correct pitch, to read the intervals in the music. How was I going to survive under these conditions? I wasn't fearful. I sing because I enjoy it, not to win the choir Director's approval. But I had this nagging suspicion that I just couldn't do it.

Everyone was initially accommodating. They all appreciated the fact that I at least had showed up. But it was the other 15 per cent of the Woody Allen proverbial that worried me. I struggled. It was one of those pieces that had each of the four voices entering at different times and I was either coming in too late or entering on the wrong note. I was getting frustrated and so were others. At first, I argued (to myself, of course, because I've learned you never argue outwardly with the structuralist approach I have come to associate with most choir directors): how can they not even begin to appreciate how difficult it is for someone who is innately very musical (even an arranger of sorts) but has no music background. I'm doing very well given my limitations. Don't they realize that once I know a piece, that is, the music is resoundingly in my head, I can read the music, and faster than they can probably! Why don't they show me a little patience and give me some slack?

Painfully, I soldiered on and was ultimately very grateful when time was called. I went home frustrated and just a little furious at the palpable lack of understanding shown by my colleague choristers. I began to think that, while they may be competent choir members, they weren't very gracious people. Once at home, I verbalized my lament. Now, while I am quite musical and invariably singing (I try to tone it down at the university but do slip up on occasion), my younger daughter is a highly successful musician. She listened and was quite incredulous at my outburst that they should realize that until I hear the music in my head, the symbols on the treble and bass clef lines mean absolutely nothing to me, a musical dyslectic. Her quiet response was sobering. "Dad", she said,

"You're very clever and exceedingly quick on your feet, but I think your lack of music theory is showing. How can you know what the music notation means if you don't understand the basis on which the composer was operating?' Ouch!! Out of the mouths of babes! Here was my youngest child calmly telling me that innate ability, while useful and sometimes necessary, is not in itself sufficient. One always needs to understand the basis on which the composer (or researcher or teacher) is operating. My experience of frustration in a professionally strange context revealed to me something that I thought I know in the context of curriculum and teacher education: that uninformed (sometimes misinformed and definitely under-theorized) practice frustrates both learners and learning. But my professionally strange context was also a gift that permitted me to grasp how theory nourishes our minds and invisibly repairs them.

\section{How Does This Occur in Teacher Education?}

As teacher education researchers, we sometimes frame our studies around usedriven and narrowly functional conceptions of practice that render our inquiries 
somewhat trivial. Many follow-up studies fall into this trap, in that they end up parading data gathering as if it were fully conceptualized research. Far too many studies in teacher education research fail to account for historical, social, cultural, and political contexts, particularly those that study teacher education programs. This was a source of considerable disquiet for me when, more than 20 years ago, I was Director of the Centre for the Study of Teacher Education here at UBC. There were some faculty colleagues who looked on the Centre as an agent of sophisticated institutional analysis and planning for the Teacher Education Office, providing data that would assist policy decisions taken around the program; whereas I wanted to conduct studies that looked at, for instance, how practicum supervision was influenced by gender and politics, that examined how issues of social justice in complex multicultural settings were addressed, and that investigated the institutional marginalization that occurs in teacher education when there is a manifest lack of commitment by professors who welcome a reward system that undermines serious attention to the institutional text of teacher education. This problematic trap has also been recognized by leading teacher education researchers like Cochran-Smith and Zeichner (2005) who attempted to draw the field of teacher education research together around important conceptualizations so that the study of, for example, demographics, indicators of quality, the effects of coursework in other faculties on teacher candidates' understanding of content and pedagogy, the relationship between methods courses and field experiences, and the thorny political and substantive question of accountability of both programs and individual candidates' performance, could be undertaken in theoretically-informed ways. For example, we know that the teaching workforce is not representative of the ethnic, cultural, and linguistic backgrounds of the diverse student population in today's schools. Such a situation calls for sharp and innovative studies that examine the impact of a hidden, taken-for-granted cultural bias toward the perpetuation of white teachers on the learning of indigenous, immigrant, and marginalized children. Such studies need to come up with bold conclusions and recommendations for policy and practice in teacher education-in policy, perhaps changes to how we appoint teacher educators, and in practice-perhaps not relying on GPA as the important admissions criterion. In moments when we are tempted to fall into this narrow and ultimately unfulfilling trap (of thinking that poorly conceptualized research is better than no research!), our teacher education researcher minds need the nourishment and challenge of curriculum theory to ensure that the inquiries we do become substantively non-trivial in the way that they generate worthwhile teacher education knowledge.

As educators of teachers, we sometimes present our subject matter content without regard for its vitality as a slice of the world we inhabit and experience. There have been too many examples of teacher educators subscribing to theoretical discourses, such as gender, race, power, social justice, etc., and yet teaching along lines imprisoned within the cage of the Tylerian rationale. Our teaching is impaired because it is forged within the narrow and technologically irres- 
ponsible crucible of the Tylerian design. Halvorson (2011) argues that Tyler's Rationale is a technological design, designing a myriad of other curriculum designs that go on designing.

In our making of programs, courses, and learning experiences, we, as curricula designers, make worlds, and they make us. We experience the indwelling between two worlds... What is most problematic here is that Tyler's design patterns continue to structure the weft of our institutional texts like the weaver's warp. And, that our designing is a warping, often escapes consideration. For, while we continuously imagine new ways to weave within our institutional texts, the more we weave within them, the more warped it seems our weaving becomes (p. 28).

Hence, there is a problem with how curriculum theory connects with teacher education. The paradox that we teacher educators now encounter as curriculum designers is that "creation is ever co-joined with destruction" (Fry, 1999: p. 52). That is, in all curriculum making, some ground must be cleared. The ground that Tyler has irresponsibly cleared with his technologies, that "like a weaver's warp goes on designing our designing" (Halvorson, 2011: p. 28), are the sites of teaching and study. Tyler's design has transformed teaching into instructional technology and reshaped study into learning technology. What is most significant about his clearing of this ground is not that it is a phenomenon in design, but that it continually escapes consideration by designers. That is, while it has been recognized by some, notably Pinar (2006), our continued failure in curriculum design (as a technological bringing forth of worlds), that we have inherited from the promulgation of the design patterns in Tyler's thinking, lies in not "taking account of and responsibility for, what is destroyed" (Fry, 1999: p. 52). This failure is a consequence of the illusion that Tylerian learning and instructional technologies constitute universal instruments. The critical point Halvorson makes is that, in the shift of Tyler's technologies away from their original niche in the context of the eight-year study into the heart of institutional curriculum discourse, those technologies have become dangerously concealed and unrecognized. Such concealment permits them to act irresponsibly as an illusion that negates educational futures because it neglects, if not dismisses, the co-creative subjectivity of students and teachers. Therein lies the technological irresponsibility in Tyler's curriculum design; it has transformed teaching into instructional technology and reshaped study into learning technology, a turn that leads to irresponsible world making in the education of teachers.

\section{Study as the Site of Education}

How does curriculum theory enable responsible world making in teacher education? A spot of time occurred for me when I came across Pinar's second edition of What is Curriculum Theory? It contains a seminal idea that sheds light on responsible curriculum making, nourishing and invisibly repairing my mind. "Study [not learning] is the site of education" (Pinar, 2006: p. 120). We acquire 
knowledge and insight through the struggle of study for which every individual has the capacity, though not necessarily the will. Teaching and learning may disseminate knowledge but study enables understanding. Study arises not from compliance with instructions but from an aspiration to understand the shifting vicissitudes between self and circumstances. Here, Pinar is rectifying Tyler's distorted emphasis on learning technology.

As Pinar declaims, "Not instruction, not learning, but study constitutes the process of education" (p. 112). Study, then, is central to self-formation, or Bildung as the Germans would say. Bildung arises from our appropriation of what is around us in the world; study builds our capacity for making choices, for developing focus, for exercising critical judgment that is so central to a wellformed character. I maintain that the absence of civic responsibility and understanding in the outcomes of K-12 schooling that was recently found in Canadian schooling by the Canadian Council on Learning Report could be explained by the fact that our conception of education is not guided by curriculum theory. There is still far too much social engineering present. As Pinar says, "if only we make the right adjustments-in teaching, in learning, in assessment-it will hum, and transport us to our destination, the promised land of high test scores" (p. 109). He goes on to say, most strikingly:

Instead of study, we have "learning" tied tightly, of course, to assessment and instruction... Because learning limits study to what is taught, it performs the dirty work of accountability, that covers for the closure of academic-intellectual-freedom in contemporary classrooms... [and structures] the "governmentality of the self", the mass production of docile workers and uncritical consumer citizens... This is the political point of accountability... to force teachers to force children-especially those "left behind"... - to accept "new" norms: docility, dependence, and an unquestioning trust of authorities (pp. 116, 119).

Tying learning to assessment and instruction creates, according to Pinar, two traps: 1) the intellectual trap that makes students dependent on teachers for learning, and 2) the political trap, that holds teachers entirely responsible for student learning (Pinar, p. 120). Equally, in teacher education, when we lead teacher candidates into innovative content pedagogy using instrumentalist techniques, we place false expectations and irresponsible curriculum designs on prospective teachers.

Thus, Pinar's seminal idea about study's central place in education shows how current policy and practice in K-12 schooling and teacher education violate the attainment of learning through its misplaced and instrumentalist direct focus on learning in and of itself. Here permit me to juxtapose learning with happiness. We all want to be happy in some shape or form, and I dare say that all students want to learn. But the direct pursuit of them makes their attainment elusive. In other words, to focus narrowly and directly on either learning or happiness is to miss out because both sneak up on us when we least expect it. Happiness occurs 
when we become absorbed in meaningful activities and relationships; likewise, learning occurs, as Dewey (1997) has said, as a by-product of meaningful activity, that is, when we embrace the hard work of wise study and eschew a vacuous focus on learning, so central to the current audit culture that reifies the Tylerian cage.

\section{So, Where Does Pedagogy Fit with Study?}

Pinar's declamation is that if we separate pedagogy from curriculum, we risk inflating the importance of the teacher's role in learning, thereby leading to a misplaced and instrumental emphasis on technique at the expense of study. And yet I would argue that it is equally important that we attempt to understand the complex role that teaching plays in contributing to new, as-yet-unanticipated possibilities in learning. Hence I am here attempting to go beyond Pinar's rightful separation of teaching from learning to grapple with what it is that teachers need to do in order to nurture appropriate curriculum conditions that propel all students in differentiated ways toward assiduous focused study to expand their minds through the understanding of new ideas. This is how I conceive of pedagogy. It is different from the form of teaching that is seen as directly accountable for student learning in that it is neither instrumental nor behavioristic. Rather it consists of teachers and teacher educators engaging in a complicated conversation-or curriculum thinking-about how their students' and their own subjectivities can be potentially re-constructed through activities framed around the subject matter content that is central to teaching. Dewey (1997) puts it like this:

When the parent or teacher has provided the conditions which stimulate thinking and has taken a sympathetic attitude toward the activities of the learner by entering into a common or conjoint experience, all has been done which a second party can do to instigate learning ... [When teachers] give the pupils something to do, not something to learn; and the doing is of such a nature as to demand thinking, or the intentional noting of connections; learning naturally results... (pp. 154, 160.)

For Dewey, then, when teachers focus directly on learning (as the neo-liberalist audit culture exogenously compels them to do), rather than on the conditions and intentional activities that foster learning, they miss the point of pedagogy and their students miss out in learning opportunities. As he says so trenchantly, "frontal attacks are even more wasteful in learning than in war" (p. 169). Hence, the aim of pedagogy is to foster student engagement, reflection, and experience through carefully thought-out activities that promote study. Nowhere is this more salient and appropriate than in teacher education.

What I am arguing for is for a conception of pedagogy in teacher education that addresses the curriculum indirectly. This suggests, like Pinar, that pedagogy must always be subject to curriculum; but it goes beyond Pinar in claiming that, while the stimulus for thinking about educational activities always arises from the curriculum, the actual making or design of those activities in keeping with 
the curriculum aims and content is also an important focus in itself. And my claim is that this important focus constitutes pedagogy. In teacher education, a more technical discourse of pedagogy constructs the world of institutional text, thereby determining what teacher educators $d o$. I argue that, if we are interested in how and what school students learn and particularly keen to change the institutional context in which teacher candidates learn to teach, then we need to understand how teacher educators create the educational activities that they use to enact the curriculum. Why is this important? It is important precisely because a pedagogical perspective enables the enactment of re-directive practices when teacher educators do not fully integrate the curricular aims they are working toward with the activities they choose. Hence, a pedagogical focus differs from a curriculum one in that it encompasses both how teacher educators can address the curriculum indirectly and also how their practices can be re-directed when they attempt a potentially disastrous "frontal attack" on learning, that is, ignoring meaningful activities, that often leads them into the instrumentalist trap.

My position then is that teacher educators need to live in the tension between curriculum understanding and curriculum enactment that I'm calling pedagogy. Living in the tension, as I do, does not deny the rightful respective perspectives of curriculum and pedagogy; rather, it demands a complicated conversation between the two. The purpose of such conversation is to make curriculum creation "emphatically intellectual, the medium of subjective and social reconstruction" (Pinar, 2011: p. 195) by riskily grappling with how the curriculum enactment process of selecting and organizing study-promoting educational activities is complicated by one's subjectivity, history, and society in framing the subject matter content of teaching. To go there in such conversation is undoubtedly risky. Pinar (2011: p. 195) maintains it could easily degenerate into "re-inscribing" a technicist notion of design that is solely an "organizational emphasis." Instead, I argue that it must focus on examining the past to understand how decisions were made that influenced the provision and presentation of study-promoting educational activities, particularly those instances wherein inappropriate attempts were made to launch a direct, frontal attack on learning. The purpose of such pedagogical examination is not to re-inscribe direct and inappropriate frontal attacks on learning but to understand how the practices that reinforced such study-denying possibilities can be reconstructed and re-directed. As Maya Angelou (1993) (http://poetry.eserver.org/angelou.html) has written, History, despite its wrenching pain/Cannot be unlived, and if facedl With courage, need not be lived again. Hence, pedagogical reconstruction involves not falling into the trap of aligning design with Tyler's rationalist cage, but rather understanding how inappropriate decisions around approaches to learning can be re-directed to practices framed around study-promoting educational activities.

\section{Curriculum Theory as Spots in Time}

It is in moments when we find ourselves given to irresponsible world making by focusing directly on learning that our teacher educator minds need the nou- 
rishment and challenge of curriculum theory to demonstrate that "other thinking [makes] other worlds (Fry, 1999: p. 95). Subject matter content presented in a way that disregards (and sometimes silences) issues of power, gender, race, identity and biography, culture and language, and social justice calls for the provocative interruption of the taken-for-granted and the evocative enlarging of the mind that curriculum theory brings. When teachers delve deeply into their subject content, they need to be equipped with conceptual frames that enable both "the making present of content to persons (Huebner, quoted in Grumet, 1978: p. 278) and the making of "persons who are made present through the contact with curriculum (Grumet, 1978: p. 278).

For example, if we present the history of Louis Riel only from the dominant White colonialist perspective of the time, we do not only a disservice to students' understanding of history but also an offence to the large non-White and First Nations' people of Canada, thereby forfeiting a glorious opportunity to connect learning to important contemporary issues of social justice in our understanding of Canada's formation. Instead, we need to create opportunities for first-hand encounters with historical and current education policy documents that might inform beginning teachers' understanding of their work with students from marginalized groups. Specifically, we could use artistic, musical, literary, mathematical, scientific, or social cultural documents in our work with pre-service teachers to help them learn how to work more effectively with students whose cultural, racial, religious and economic backgrounds are different from their own. That is, we could work toward cultivating a disposition toward encountering artistic, musical, literary, mathematical, scientific, or social cultural knowledge (e.g., in the form of archival documents and narratives) not only as artifacts from the past but also as something that makes ethical demands on us here and now.

For example, if we present the symbolic language of mathematics as something that is linear, predictable, and non-interpretable, then we not only reinforce a popular error in students' understanding of mathematics but also seriously restrict their ability to grasp the elegant geometry of number patterns that mathematical thinking permits, because we do not address the error's taken-for-granted assumption that our accepted number system has a basic place value of ten (10), thereby denying that mathematical language (like any other) is indeed a human construction. Instead, we need to pose problems that engage students in grappling with mathematical periodicity as a form of repeating geometric patterns, such that, if the place value were to be changed from ten to, say, five or six, they could easily work out addition, subtraction, multiplication, and division, because they would understand the following representation framed as a decimal number with six places:

\section{N6 N5 N4 N3 N2 N1 1. 1/N1 1/N2 1/N3 1/N4 1/N5 1/N6}

In addition, we could tap into students' real-life mathematical experiences as teaching points by presenting problems with a context, thereby prompting students to ask questions related to why prices are higher in certain stores or why 
certain items are not sold individually, questions that permit students to use mathematics to "read the world" (Freire, 1970: p. 75). We can further teach quantitative literacy by identifying, understanding, and addressing issues that arise from the fairness of distribution of the benefits and burdens entailed in living in a community. In this way, mathematics becomes a critical ingredient (though not the only one) in the formation of informed and engaged citizens in contemporary democratic society. This healthy appreciation of social justice arises from the theoretically informed presentation of mathematical content.

Another example would be if we present the music of Robert Schumann (born 200 years ago) as if it stemmed entirely from his apparent genius, then we dismiss the generative influence (and, in some instances, actual composition) that Clara Wieck, his wife, made on and for the quality of the music, thereby reinforcing an unfortunate and insensitive myth that men were composers and women listeners, and forfeiting the opportunity to show that music is not the product of patriarchy. In such instances, we need our thinking to be challenged and disrupted.

\section{Conclusion}

Curriculum theory informs, evokes, provokes, and disrupts our mental frames about teaching. This is a highly complex undertaking. To be creative in our approach to the education of teachers, we need the theoretically informed conceptualization of studies that comment powerfully on the policy and practice of teacher education. In our role as teacher educators, we need purposefully to elude the Tylerian "cage" that severely diminishes possibilities in learning in favor of a re-conceptualized appreciation of how we design the curriculum for learning to teach. The significance here is that we need to enliven teacher education and that curriculum theory, properly understood, has a vital role to play. Without this, teacher education, in most of its iterations, will not be creative but likely remain moribund; and, if teacher education as a viable practice dies, then so too will Faculties of Education. We need curriculum theory to help us find spots in time whence our minds as teacher education researchers and pedagogues are nourished and invisibly repaired. Without this laparoscopic ${ }^{1}$ intervention, we will ultimately cease to be.

\section{References}

Angelou, M. (1993). Inaugural Poem. http://poetry.eserver.org/angelou.html

Bolton, G. (2010). Reflective Practice: Writing and Professional Development. Thousand Oaks, CA: Sage.

Cochran-Smith, M., \& Zeichner, K. (Eds.) (2005). Studying Teacher Education: The Report of the AERA Panel on Research and Teacher Education. Mahwah, NJ: Lawrence Erlbaum Associates, Inc.

Dewey, J. (1997). Democracy and Education: An Introduction to the Philosophy of Education. New York: Free Press.

${ }^{1}$ Invisible laser surgery is that which repairs internal injuries without disrupting the body or breaking the skin. 
Freire, P. (1970). Pedagogy of the Oppressed. New York: Continuum Books.

Fry, T. (1999). A New Design Philosophy: An Introduction to Defuturing. Sydney, Australia: University of New South Wales Press.

Grumet, M. R. (1978). Bitter Milk: Women and Teaching. Amherst, MA: University of Massachusetts Press.

Halvorson, M. (2011). Revealing the Technological Irresponsibility in Curriculum Design. Curriculum Inquiry, 41, 34-47. https://doi.org/10.1111/j.1467-873X.2010.00523.x

Pinar, W. F. (2006). The Synoptic Text Today and Other Essays: Curriculum Development after the Reconceptualization. New York: Peter Lang.

Pinar, W. F. (2011). The Character of Curriculum Studies: Bildung, Currere, and the Recurring Question of the Subject. New York: Palgrave Macmillan. https://doi.org/10.1057/9781137015839

Wordsworth, W. (1850). The Prelude or, Growth of a Poet's Mind: An Autobiographical Poem (Book XII). New York: Appleton \& Co.

Submit or recommend next manuscript to SCIRP and we will provide best service for you:

Accepting pre-submission inquiries through Email, Facebook, LinkedIn, Twitter, etc. A wide selection of journals (inclusive of 9 subjects, more than 200 journals)

Providing 24-hour high-quality service

User-friendly online submission system

Fair and swift peer-review system

Efficient typesetting and proofreading procedure

Display of the result of downloads and visits, as well as the number of cited articles

Maximum dissemination of your research work

Submit your manuscript at: http://papersubmission.scirp.org/

Or contact ce@scirp.org 